International Journal of Hiology, Pharmacy and Allied Seiences (IJBPAS) 'A Bridge Betuen Caboratory and Qnendo'

WwW.ijbpas.com

\title{
SAFETY PRACTICES AMONG DENTISTS AGAINST COVID-19
}

\section{JAYADHARANI $\mathrm{C}^{\mathbf{1}}$, GHEENA $\mathrm{S}^{\mathbf{2}^{*}}$, LAKSHMANAN $\mathrm{G}^{\mathbf{3}}$}

1: Department of Dental Anatomy, Saveetha Dental College and Hospital, Saveetha Institute of Medical and Technical Sciences, Chennai, India

2: Associate Professor, Department of Oral Pathology, Saveetha Dental College and Hospitals, Saveetha Institute of Medical and Technical Sciences, Saveetha University, Chennai, India

3: Department of Anatomy, Saveetha Dental College and Hospitals, Saveetha Institute of Medical and Technical Sciences, Chennai, India

*Corresponding Author: E Mail: Dr. S.Gheena: gheena@saveetha.com; Tel: +919884033777

Received 19 ${ }^{\text {th }}$ March 2021; Revised 20 ${ }^{\text {th }}$ April. 2021; Accepted 19 ${ }^{\text {th }}$ May 2021; Available online $1^{\text {st }}$ Aug. 2021

\section{https://doi.org/10.31032/IJBPAS/2021/10.8.1003}

\begin{abstract}
The safety of the healthcare system as given by national health performance committee is defined as the avoidance or reduction to acceptable limits of actual or potential harm from the healthcare management or the environment in which healthcare is delivered. Dental workers are at risk of many hazards including pathogens, pharmaceuticals, ergonomic and psychological hazards. Control measures or risk controls are measures we put in place (PPE) to reduce those hazards. Even the dental practitioners are at a higher risk of acquiring many infectious diseases and especially vulnerable in a pandemic situation like COVID-19. A questionnaire was distributed through online google forms link to about 100 dental students and practitioners, the study population was asked to fill out the online form after reading each question thoroughly. The results were collected and the data was analysed using SPSS version 20. The results showed that the responders had a good level of knowledge about Covid-19, Safety practices among dentists against Covid 19 and among that $75 \%$ of dental practitioners were aware that the Dentist population is placed at the highest risk of infection and only $18.9 \%$ of the participants were aware of suitable Personal Protective Equipment (PPE) to avoid the infection. This study gives an insight on the Dental practitioners perception towards the Safety practices Against Covid-19.
\end{abstract}

Keywords: Covid-19; Dental practitioners; Safety practices; PPE 


\section{INTRODUCTION}

The Covid 19 virus was recently identified in the saliva of infected patients. Saliva can have a pivotal role in human to human transmission. Dentists and other healthcare professionals who perform aerosol generating procedures may be unknowingly providing direct and indirect care for infected but not yet diagnosed Covid 19 patients, or those considered to be suspected cases for surveillance [1]. Therefore, it is crucial, to come up with protocols for dentist to refine preventive strategies to avoid the covid-19 [2] infection by focusing the Hand hygiene and using all available personal protective equipment (PPE). It would be ideal that the dental services be limited to only urgent and emergency visits during this period of the pandemic [3]. Wherever possible, these actions help dental practitioners stay safe, preserve personal protective equipment and patient care supplies and expand available health system capacity [4]. Wearing a surgical mask and eye protection with solid side shields or a face shield to protect the mucous membrane of the eyes, nose and mouth during procedures likely to generate splashing or spattering of blood and other body fluids [5]. Changing Masks should be done between patients or during patient treatment when the mask becomes wet [6].
If any urgent dental treatment is necessary, DHCP (Dental Healthcare Personnel) and medical providers should work together to determine the appropriate protocol of precautions on a case-by-case basis [7]. To avoid the potential spread of the disease among patients visitors, transmissions based precautions that are recommended for the Hospital and other ambulatory care setting [8] are to be followed, Medical providers will need to determine whether the facility is an appropriate setting for the necessary service for the infectious patients $[5,9]$.

Basically, for any infection control strategies, dentists should be aware of individual protective measures and appropriate sterilization or other high-level disinfection utilities. Other than infectious diseases, strained posture at work disturbs the musculoskeletal alignment and leads to a stooped spine [10]. The stooped posture also involves certain groups of muscles and joints [11]. This may lead to diseases of the musculoskeletal system [12]. Continuous education and appropriate intervention studies are needed to reduce the complication of these hazards [13]. So, it is important for dentists to remain constantly up-to-date about measures on how to deal with newer strategies and dental materials, and 
implicates the need for special medical care for this particular professional group [14]. Dentistry is considered by the practitioners and most of the public as being extremely hazardous by infectious hazards: needles and other sharp objects, spatter, and aerosols that can transmit viral infections from simple to life-threatening infections such as Acquired Immuno Deficiency Syndrome and Hepatitis $\mathrm{B}$ are all faced by the dental practitioners [15]. Bacterial infections also play an important role [16]. The critical infections that should be concerned are syphilis and tuberculosis. Among allergic reactions: Gloves containing latex are the main causes of the allergic skin irritation, but dental materials, detergents, lubricating oils, solvents, and X-ray processing chemicals also could lead to allergic skin reaction [17]. The primary aim of the study is to assess and stimulate the awareness of the hazards in their profession among the dental practitioners. This survey comprises undergraduate students to working dental practitioners, to understand the awareness, among them to be used as an aid in the fight against Covid 19.

\section{MATERIALS AND METHODS}

An online survey was conducted with a selfstructured questionnaire with a sample size of 100 consisting of dental students and practitioners. The questionnaire consisted of questions related to recent findings or updates in the safety practices practiced against covid19, and finally questions related to hazards of the profession. The participants were given a short introduction about the safety practices practiced against covid19. The questionnaire was validated in the standard manner. Measures such as selection of participants randomly, steps to prevent asking irrelevant questions to the participants, placing restrictions over participant population and age groups are taken to minimise the bias occurring in sampling. The questionnaire was designed using the online survey platform "google forms". Descriptive analysis was carried out using the statistical analysis using IBM SPSS software version 20.0. Descriptive statistics were expressed by means of frequency and percentage and the results of the survey were represented in the form of pie charts and bar charts.

\section{RESULTS AND DISCUSSION}

The present study shows that it is evident that knowledge and awareness regarding the various aspects of Covid 19, safety of the dental practitioners is inadequate among the target population. Infection control issues during patient assessment like patients with acute respiratory issues should be identified 
[18]. A study on overview of transnational recommendation for Covid 19 explained the coronavirus in SARS-COV2, Dentistry Oral health transmission [19]. The present study (Figure 2) shows that $75 \%$ of the respondents were aware that dentists are placed at highest risk of infection and since all dental treatment leads to aerosols (Kardos, Kieser and Kardos, 2006) (Mace, 2017) (Bachireddy, Chen and Dar, 2020). In the present study (Figure 3) around 24\% of the participants were aware of PPE (Personal Protective Equipment) which was similar to the findings of the study conducted by [20]. In the present study (Figure 4) denotes that around $85 \%$ of dental practitioners are aware of the increasing number of asymptotic treated as Covid 19 positive when compared with our study findings was similar to the study conducted by Fazal Ghani. Study conducted by [21]. In the present study only $27 \%$ of total participants were aware of aerosol size and $73 \%$ were not aware and recorded that around (Figure 5). In the present study (Figure 6) shows that around $43 \%$ of them are aware that bronchoalveolar lavage Gets fluid has 93\% Corona testing Positivity rate and nasal swabs [22]. The results of (Figure 7) Quinn et al., 2020) shows that $40 \%$ were aware of the urgent care team which they provided with PPE and
$60 \%$ were not aware of the urgent care team and their moral duty. In the present study (Figure 8) depicts that around $43 \%$ were aware of respiratory mask which provide $99 \%$ filtration and normal surgical mask provide $80 \%$ Filtration and cloth mask very less than that which is similar to the study done by (Dr. Aditi kadam) (Mohammed tahi). Around $73 \%$ were aware of teledentistry is the preferred mode of treatment nowadays (Figure 9). In the present study (Figure 10) 39\% of the respondents were willing to be a member of organised urgent care delivery team, if provided with proper care PPE. [23, 24, 25] as recorded in the present studies.

Bar graph represents the association of gender and awareness of the Dentist population being placed at the highest risk of infection analyzed using chi-square test, $(\mathrm{P}$ value $=0.001$ ) Hence males among the study population are more aware of the dentist population being placed at highest risk (Figure 11). Bar graph represents the association of gender and awareness of PPE was done using chi-square test, Hence females are more aware of PPE (Personal Protective Equipment $)(P$ value $=0.019)$ (Figure 12). Bar graph represents the association of gender and Willingness to be a member of organized urgent care delivery 
teams by chi-square test. Hence both are equally aware of Willingness to be a member of organized urgent care delivery teams $(p$ value -0.009) (Figure 13). Bar graph represents the association of gender and awareness of Teledentistry being the
$\mathrm{P} \backslash$ preferred mode of treatment now, done by chi-square test, $(\mathrm{P}$ value $=0.000)$ implying Males are more aware of Teledentistry being the prefered mode of treatment now (Figure 14).

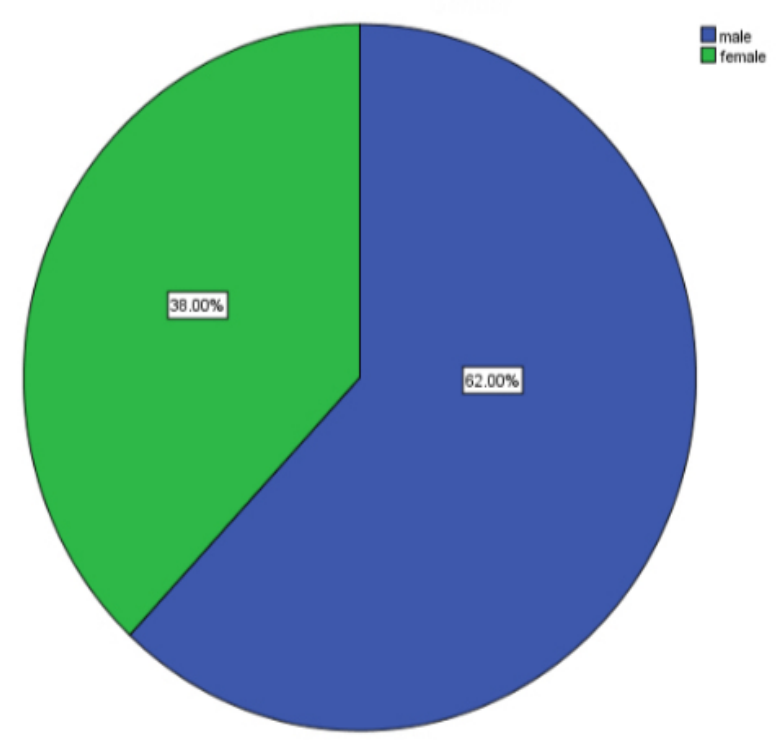

Figure 1: Pie chart represents the distribution of participants based on Gender. In the present study, it was found that $62 \%$ were Male, $38 \%$ of the respondents were Female

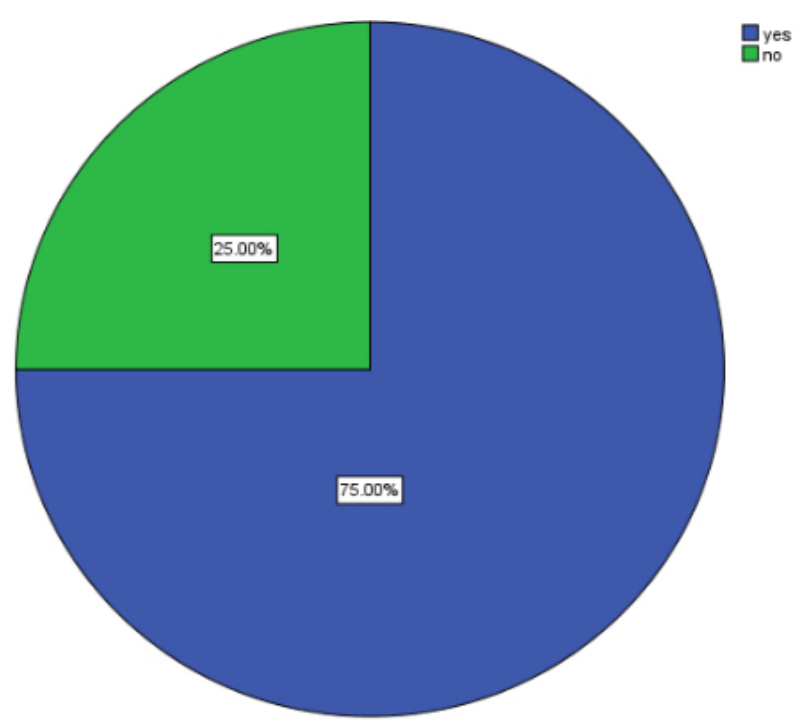

Figure 2: Pie chart shows responses for the question about awareness of high risks of infection faced by Dentists. $75 \%$ of the respondents (Blue colour) agreed that dentists are at high risk of acquiring infection and the remaining $25 \%$ (green colour.) disagreed 


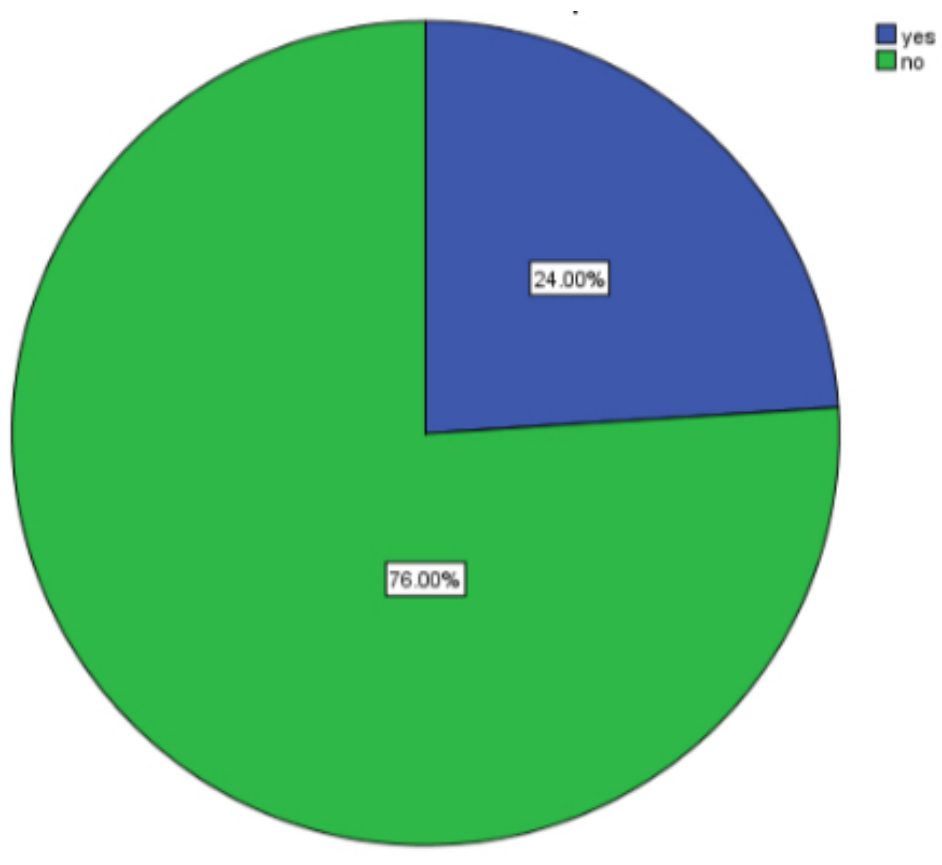

Figure 3: Pie chart shows responses for the question, Personal Protective Equipment consists of surgical gown, respirators, gloves, eye protective wear, face shield and should be used for all dental procedures, among that $24 \%$ positive responses are in (blue colour) agreed that they are aware of PPE and remaining $76 \%$ (green colour) disagreed

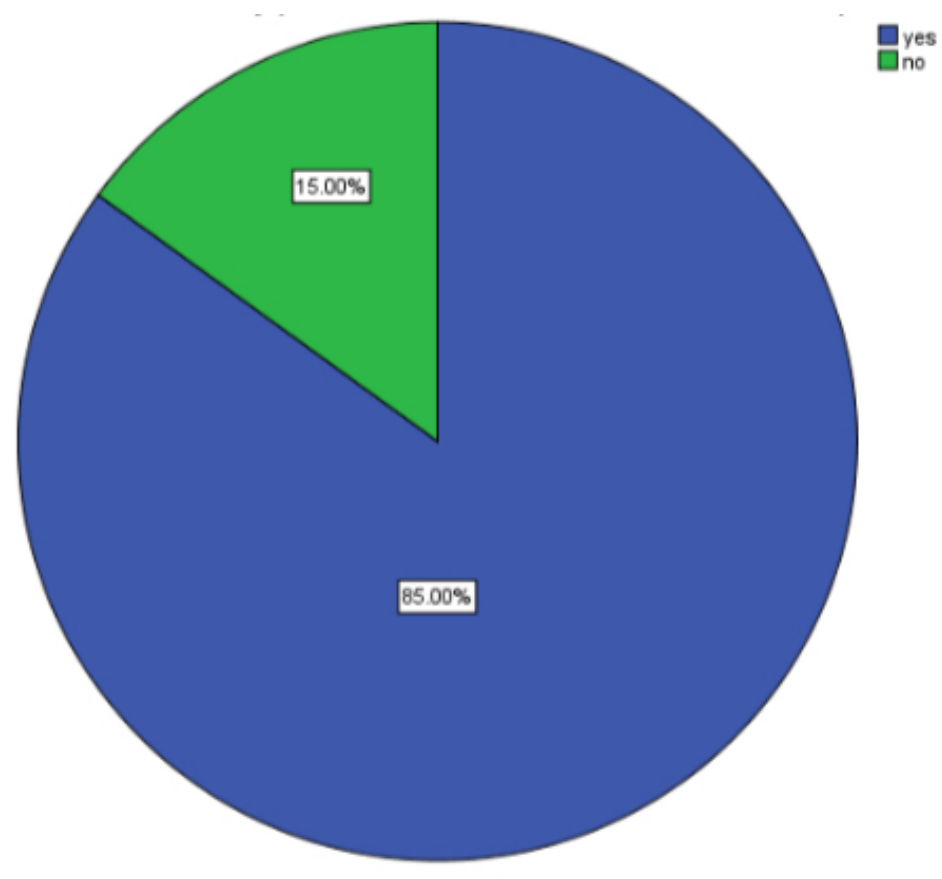

Figure 4: Pie chart shows responses for the question Increased number of asymptotic patients, is each and every patient should be treated as Covid-19 positive, among that $\mathbf{8 5 \%}$ positive responses are in (blue colour) agreed (Increased number of asymptotic patients), is each and every patient should be treated as Covid-19 positive that and remaining $15 \%$ (green colour) disagreed 


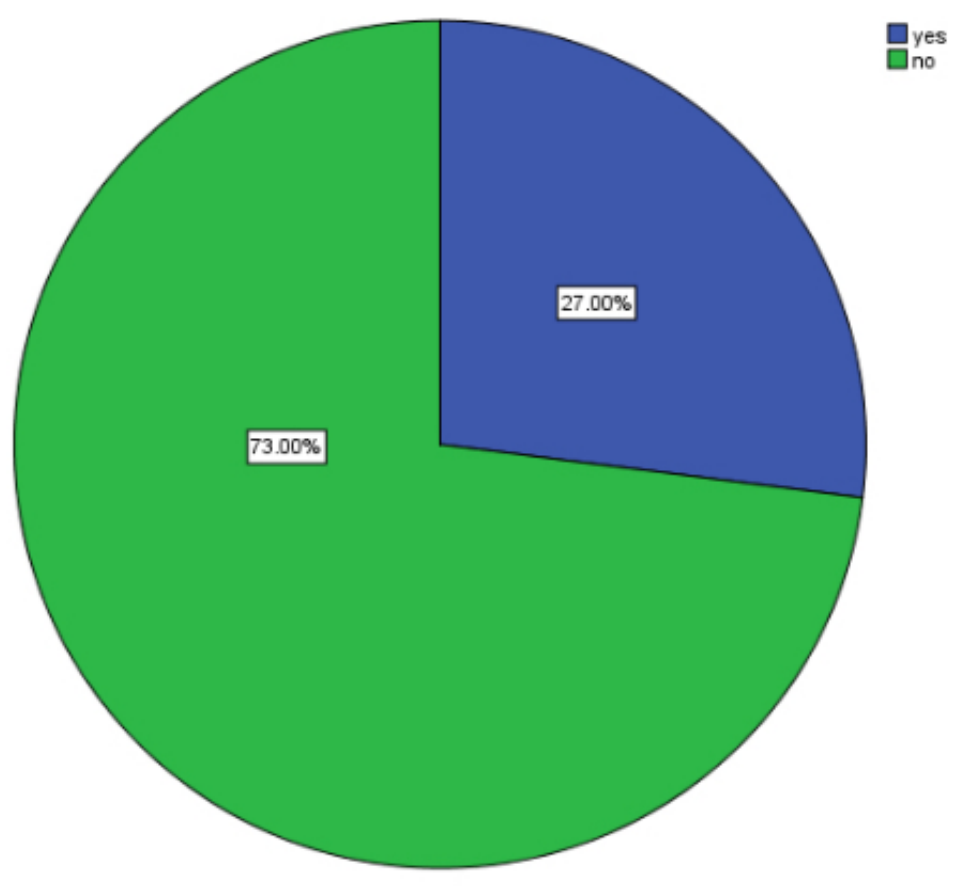

Figure 5: Pie chart shows responses for the question, COVID-19 measures around 120nm and that aerosol particulate sizes can range from $3-120 \mathrm{~nm}$, among that $27 \%$ positive responses are in (blue colour)agreed COVID-19 measures around $120 \mathrm{~nm}$ and that aerosol particulate sizes can range from $3-120 \mathrm{~nm}$ )and remaining $73 \%$ negative response are in (green colour) disagreed

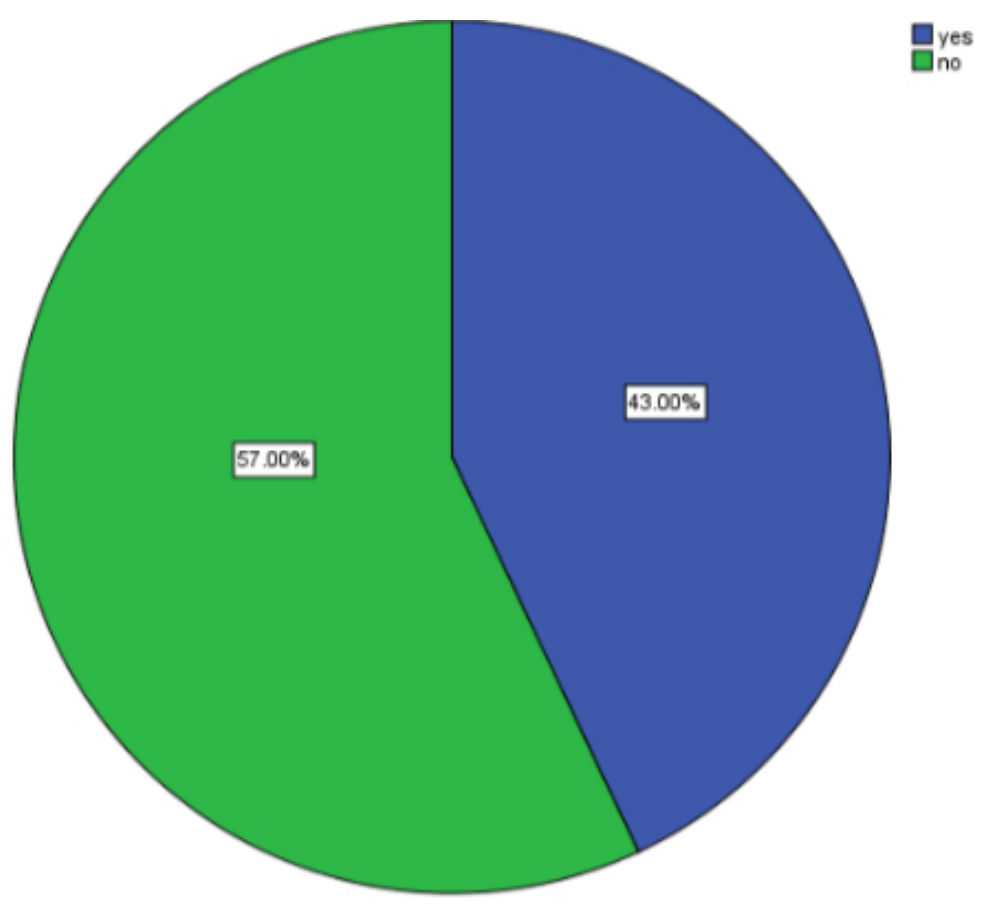

Figure 6: Pie chart shows responses for the question, that bronchoalveolar lavage gets fluid had $93 \%$ corona testing positive and nasal swabs only $63 \%$, among that $43 \%$ positive responses are in( blue colour) agreed bronchoalveolar lavage gets fluid had $93 \%$ corona testing positive and nasal swabs only $63 \%$, remaining $57 \%$ negative responses are in (green colour) disagreed 


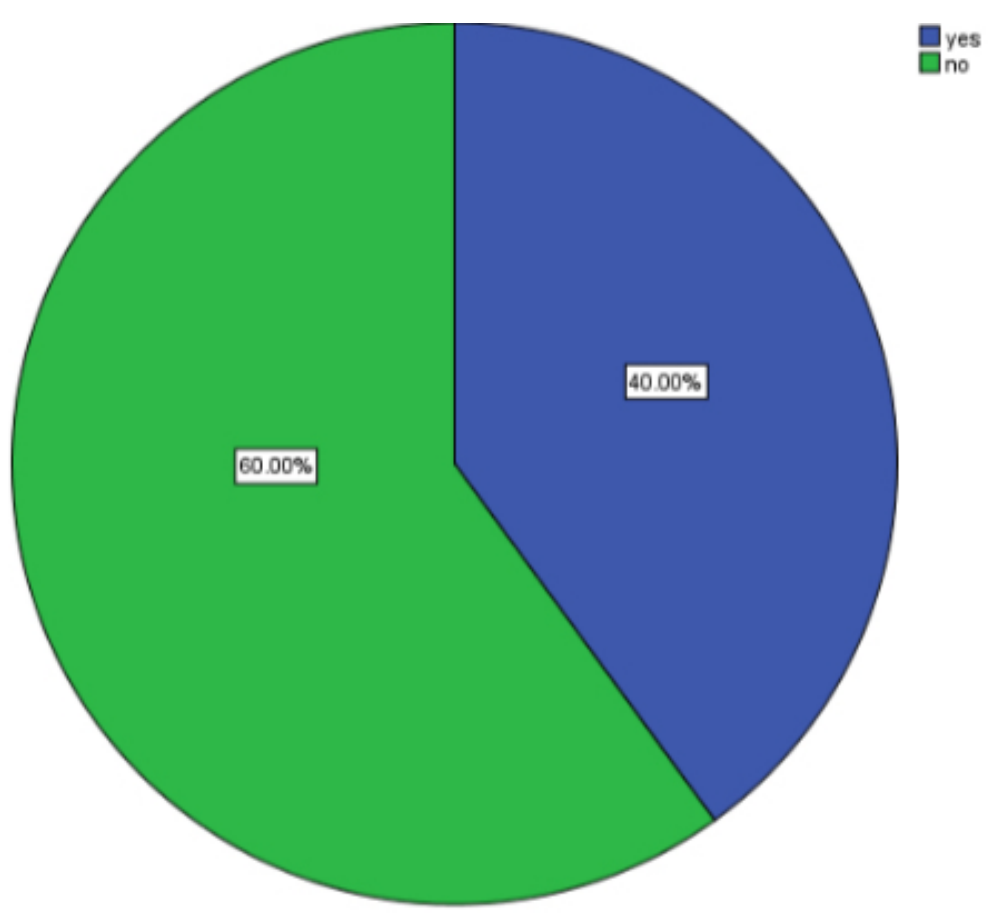

Figure 7: Pie chart shows responses for the question, believes that organized urgent care - delivery should be provided only by teams that are provided with proper care, among that $40 \%$ positive responses are in (blue colour) agreed and remaining $60 \%$ negative responses are in (green colour) are disagreed

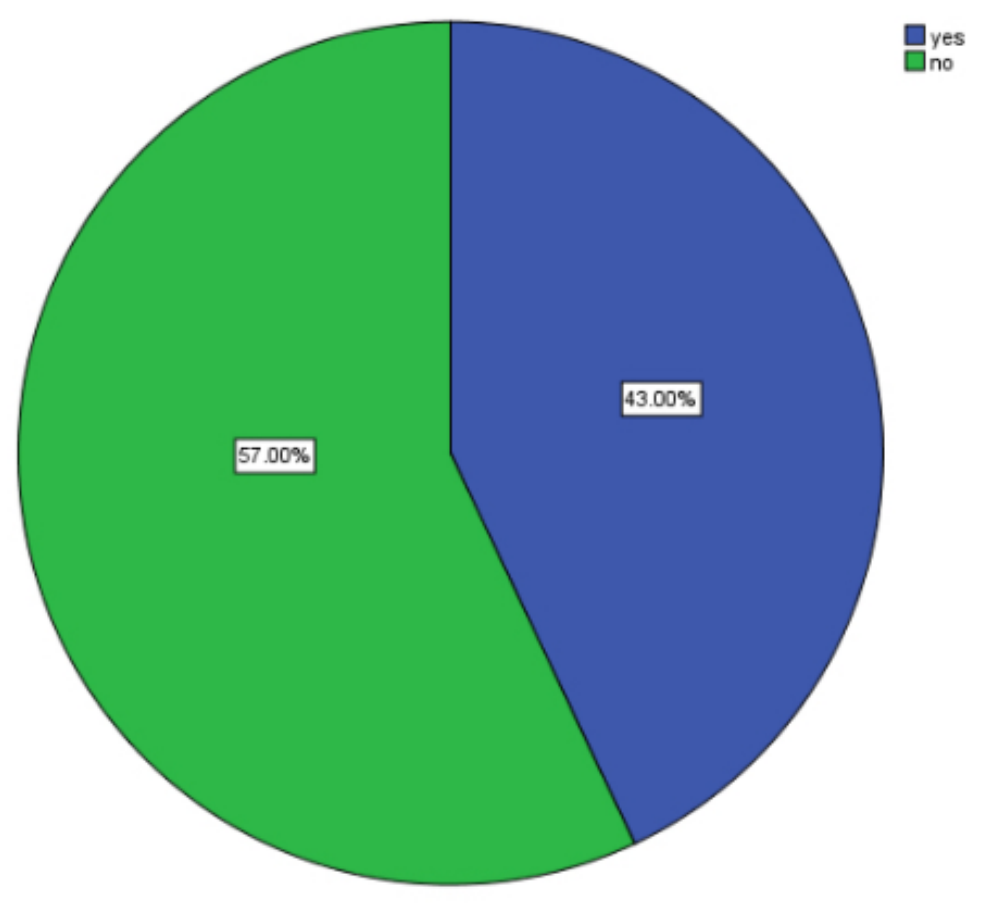

Figure 8: Pie chart shows responses for the question, respirators masks only provide $99 \%$ filtration and normal surgical masks provided only $80 \%$ filtration and cloth masks very less, among that $43 \%$ positive responses are in (blue colour) agreed masks only provide $99 \%$ filtration and normal surgical masks provided only $80 \%$ filtration and cloth masks very less, and remaining $57 \%$ negative responses are in (green colour) disagreed 


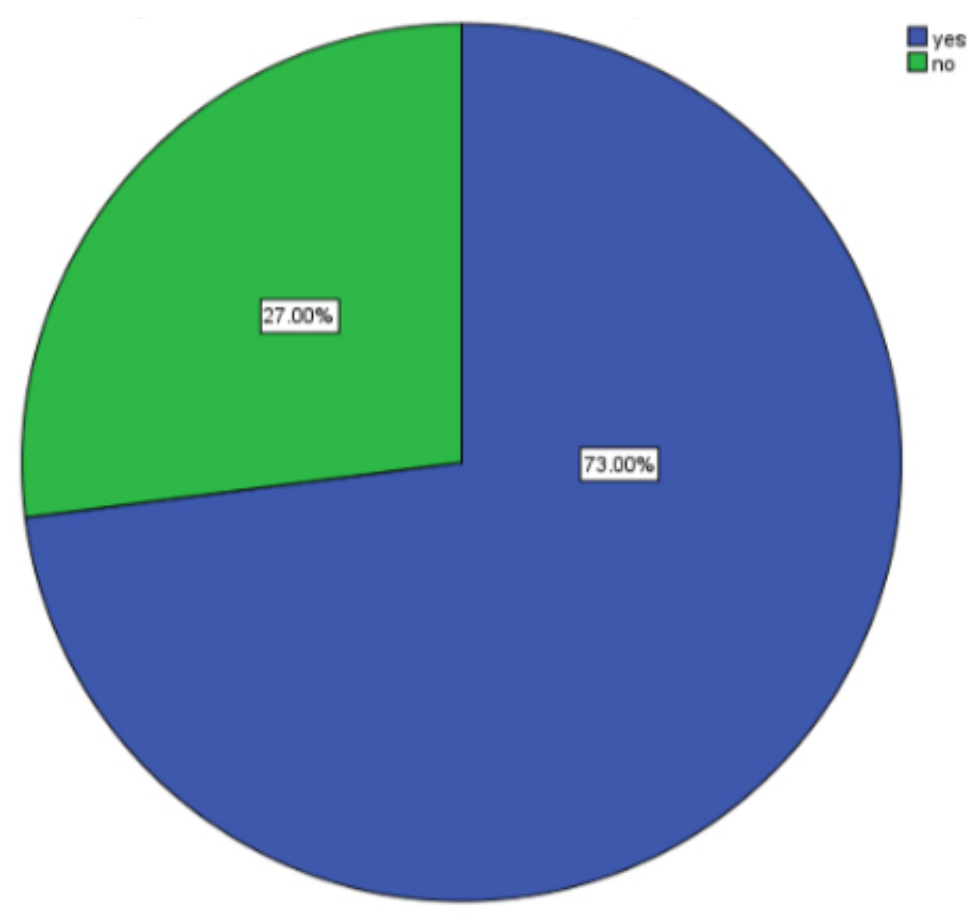

Figure 9: Pie chart shows responses for the question, teledentistry is the preferred mode of treatment among that $73 \%$ positive responses are in (blue colour) agreed that teledentistry is the preferred mode of treatment and remaining $27 \%$ negative responses are in (green colour) disagreed

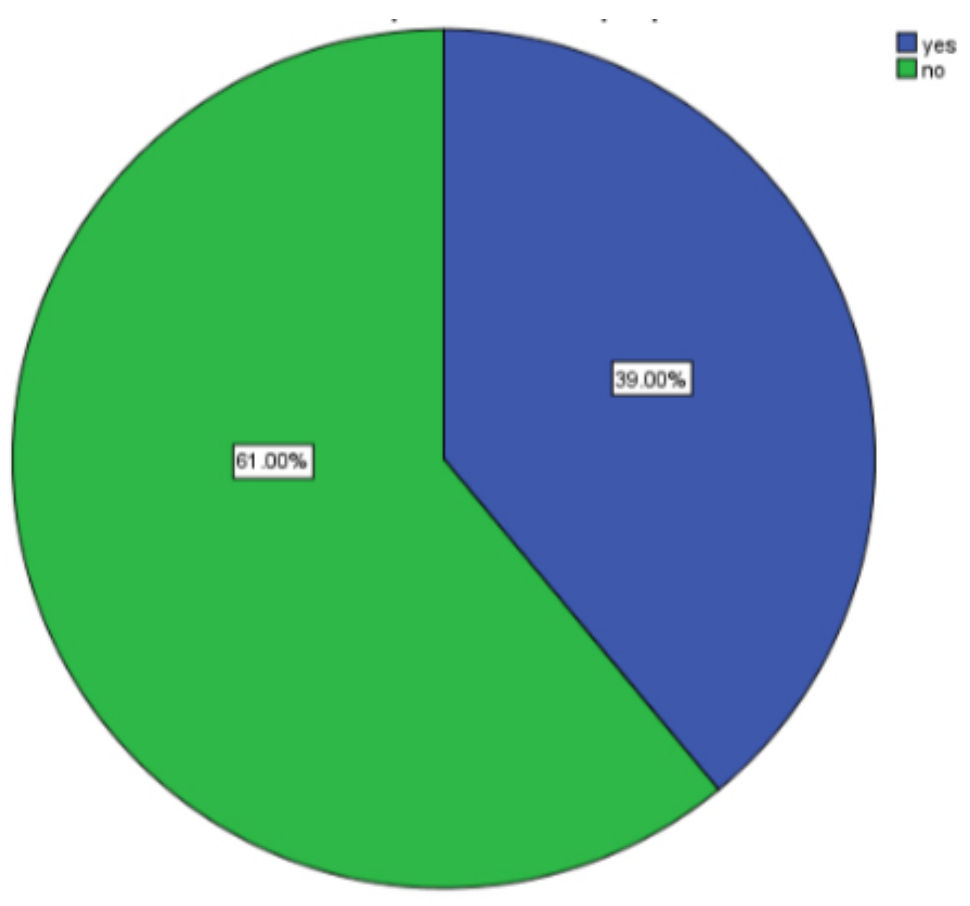

Figure 10: Pie chart Shows responses for the question, would you willing to be a member of an organized urgent care delivery team , if provided proper PPE, among that $39 \%$ positive responses are in (blue colour) agreed would you willing to be a member of an organized urgent care delivery team, if provided proper PPE and remaining $61 \%$ negative responses are in (green colour) disagreed 


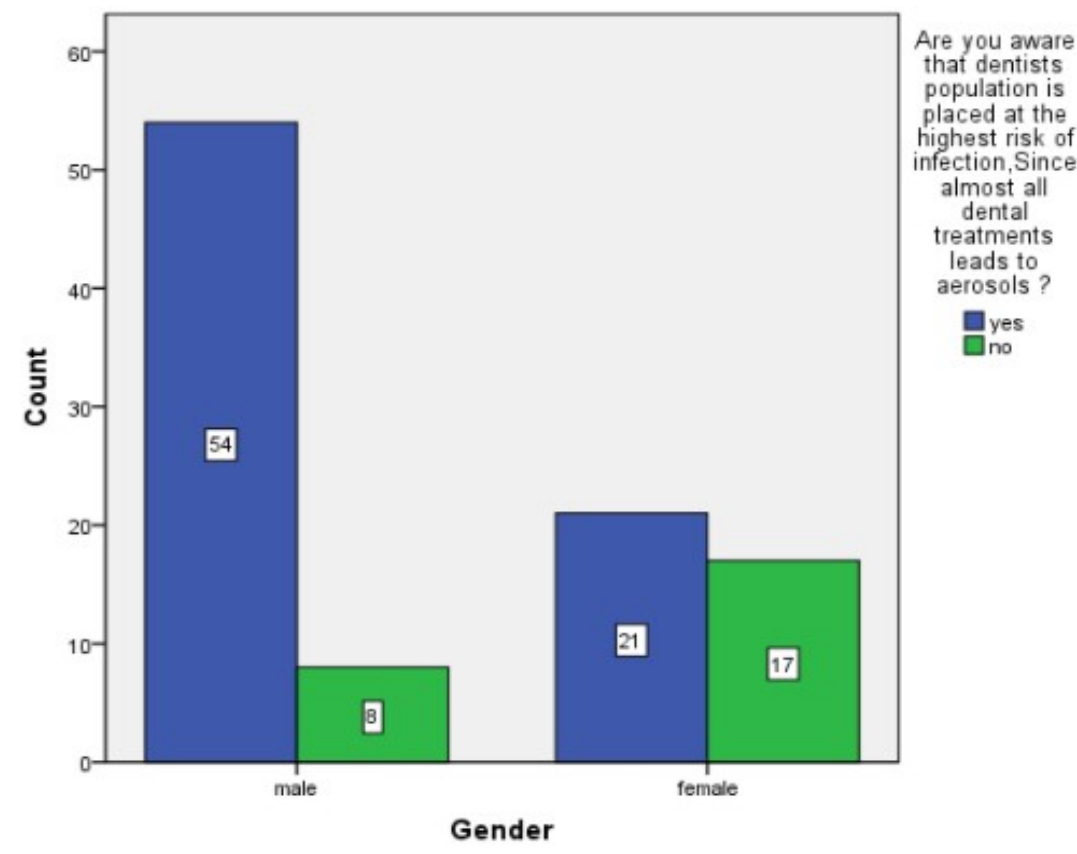

Figure 11: Bar graph represents the association of gender and awareness of the Dentist population being placed at the highest risk of infection. $X$ axis represents the gender and $Y$ axis represents the awareness of Dentists population placed at the highest risk of infection. Out of $33 \%$ of the participants who are aware (blue), $23 \%$ constitutes male and $10 \%$ constitutes female. Those who are not aware are represented by (green colour). Association between gender and awareness of the Dentists population placed at highest risk of infection was analyzed using chi-square test $(P$ value $<0.001)$ ( $p$ value $<0.05$ ), and was found to be statistically significant. Hence males among the study population are more aware of the dentist population being placed at highest risk

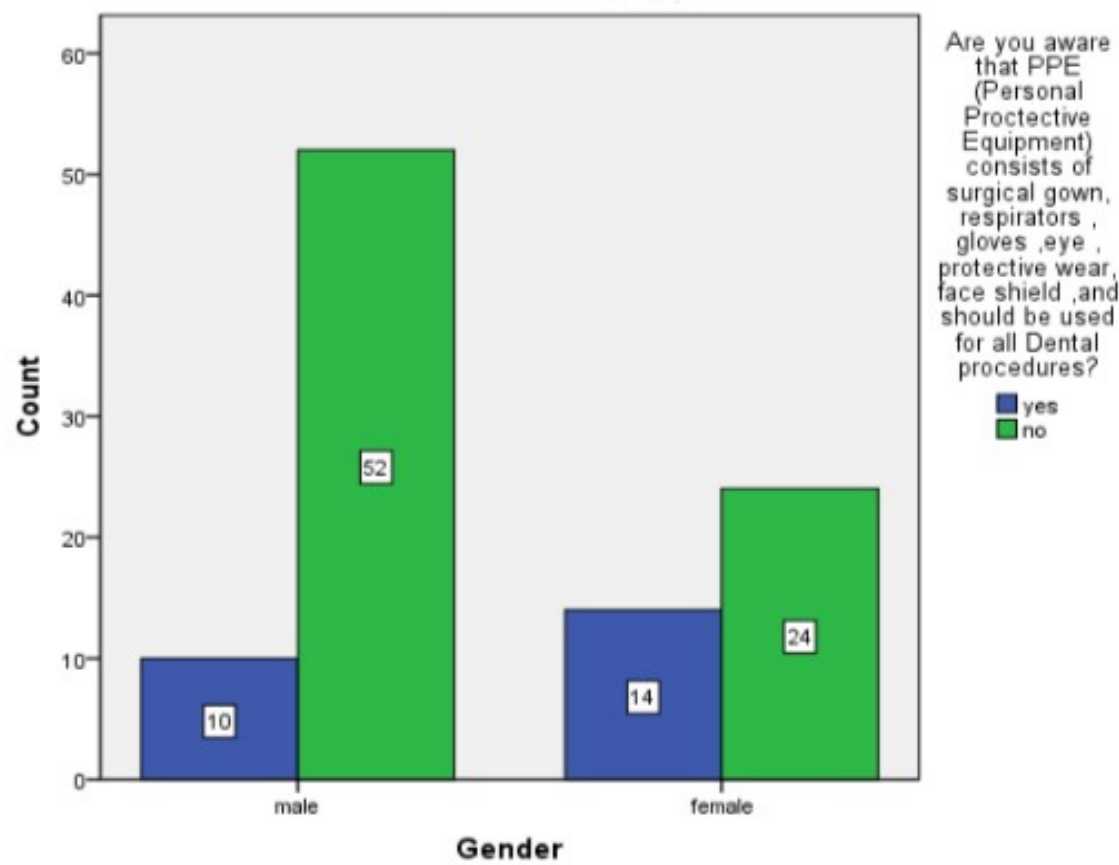

Figure:12 Bar graph represents the association of gender and awareness of PPE $X$ axis represents the Gender and $Y$ axis represents the number of responses on awareness on PPE, where those who are aware are represented by 'blue' and not aware by 'green'. Association between gender and awareness on PPE was done using chi-square test, $(P$ value $=0.019)(p$ value $<\mathbf{0 . 0 5}$ ), and was found to be statistically significant. Hence females are more aware of PPE (Personal Protective Equipment) 


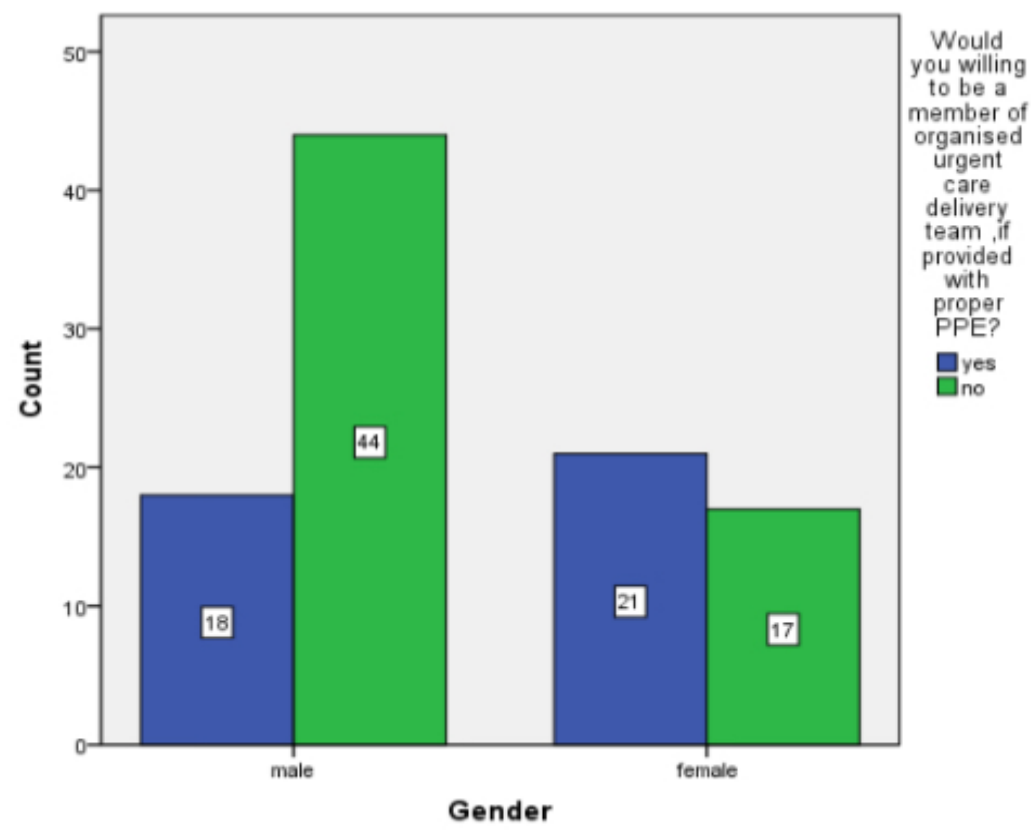

Figure 13: Bar graph represents the association of gender and Willingness to be a member of organized urgent care delivery teams. $X$ axis represents the Gender and $Y$ axis represents the no. of responses on Willingness to be a member of organized urgent care delivery teams, where those who are willing are represented by 'blue' and not willing by 'green'. Association between gender and awareness of Willingness to be a member of an organized urgent care delivery team was done using chi-square test, $(p$ value $\mathbf{- 0 . 0 0 9})(p$ value $<0.05)$, was found to be statistically significant. Hence both are equally aware of Willingness to be a member of organized urgent care delivery teams

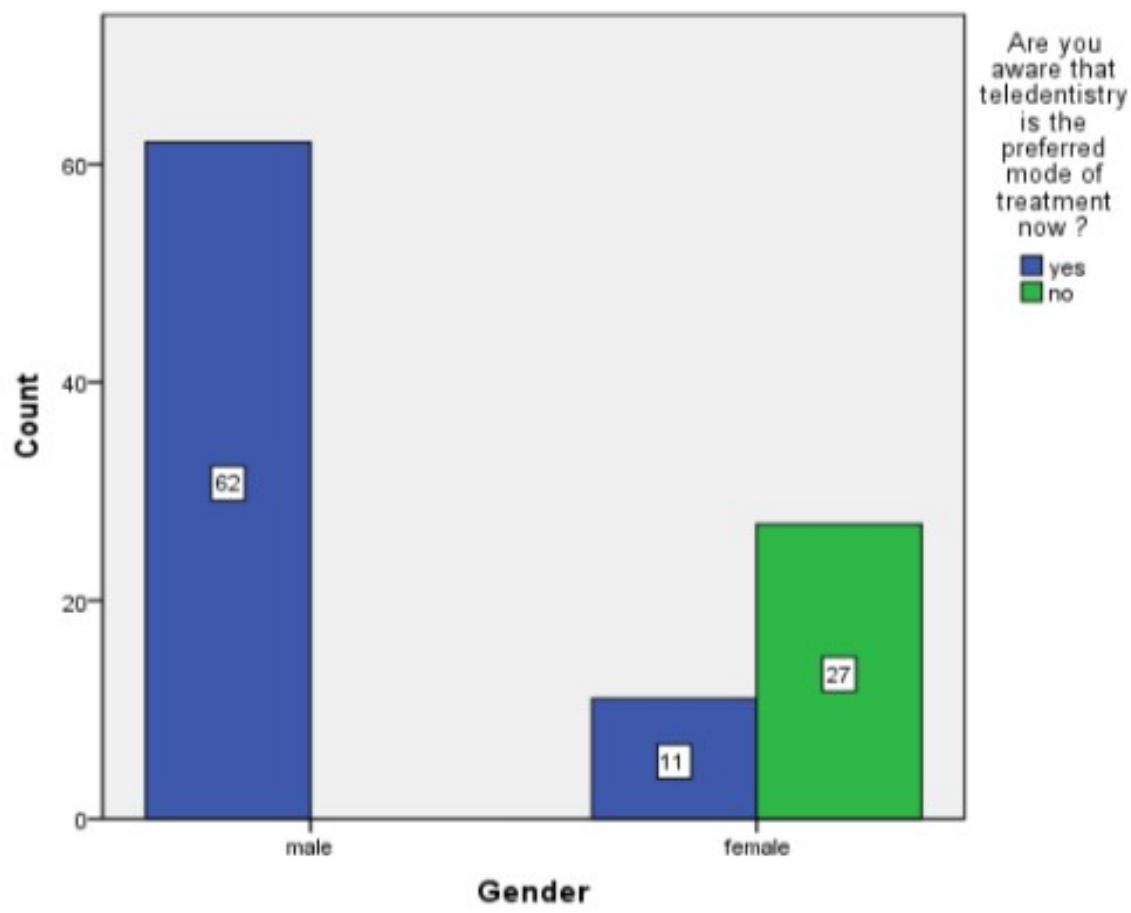

Figure 14: Bar graph represents the association of gender and awareness of Teledentistry being the Prefered mode of treatment now. $X$ axis represents the Gender and $Y$ axis represents awareness of Teledentistry being the Prefered mode of treatment now. Where those who are aware are represented by 'blue' and not aware by 'green'. Association between gender and awareness of Teledentistry as the Prefered mode of treatment now was done using chi-square test, $(P$ value $=$ $0.000)(p$ value $<0.05)$, and was found to be statistically significant. Hence Males are more aware of Teledentistry being the prefered mode of treatment now 


\section{CONCLUSION}

Within the limitations associated in the present survey performed, the study concludes that majority of the dentists are aware that during the current pandemic of Covid 19 spread most of the dental practitioners were aware of (PPE) personal protective equipment initiatives taken by the government to prevent this pandemic. We do find a lacunae in awareness on what constitutes PPE and disparity in willingness to be part of an organized urgent care delivery team. The study stresses the need for awareness programs and guidelines on Proper PPE and protocols to be followed in these trying times.

\section{REFERENCES}

[1] Spagnuolo G, De Vito D, Rengo S, Tatullo M. COVID-19 Outbreak: An Overview on Dentistry. Int J Environ Res Public Health [Internet]. 2020 Mar 22;17(6). Available from: http://dx.doi.org/10.3390/ijerph17062 094

[2] Palati S, Ramani P, Shrelin H, Sukumaran G, Ramasubramanian A, Don KR, et al. Knowledge, Attitude and practice survey on the perspective of oral lesions and dental health in geriatric patients residing in old age homes [Internet]. Vol. 31, Indian
Journal of Dental Research. 2020. p. 22. Available from: http://dx.doi.org/10.4103/ijdr.ijdr_19 $5 \_18$

[3] Meng L, Hua F, Bian Z. Coronavirus Disease 2019 (COVID-19): Emerging and Future Challenges for Dental and Oral Medicine [Internet]. Vol. 99, Journal of Dental Research. 2020. p. 481-7. Available from: http://dx.doi.org/10.1177/0022034520 914246

[4] Sritharan J, Ontario Tech University, Metrics Vocational Inc., ASKRehab, Sritharan A. Emerging Mental Health Issues from the Novel Coronavirus (COVID-19) Pandemic [Internet]. Vol. 3, Journal of Health and Medical Sciences. 2020. Available from: http://dx.doi.org/10.31014/aior.1994. 03.02.109

[5] Shree KH, Hema Shree K, Ramani P, Herald Sherlin, Sukumaran G, Jeyaraj $\mathrm{G}$, et al. Saliva as a Diagnostic Tool in Oral Squamous Cell Carcinoma - a Systematic Review with Meta Analysis [Internet]. Vol. 25, Pathology \& Oncology Research. 2019. p. 447-53. Available from: http://dx.doi.org/10.1007/s12253019-00588-2 
[6] Coulthard P. Dentistry and coronavirus (COVID-19) - moral decision-making [Internet]. Vol. 228, British Dental Journal. 2020. p. 5035. Available from: http://dx.doi.org/10.1038/s41415020-1482-1

[7] Izzetti R, Nisi $M$, Gabriele $M$, Graziani F. COVID-19 Transmission in Dental Practice: Brief Review of Preventive Measures in Italy [Internet]. Journal of Dental Research. $2020 . \quad$ p. 002203452092058.

http://dx.doi.org/10.1177/0022034520 920580

[8] Ghani F. Covid-19 Outbreak Immediate and long-term impacts on the dental profession [Internet]. Vol. 36, Pakistan Journal of Medical Sciences. 2020. Available from: http://dx.doi.org/10.12669/pjms.36.co vid19-s4.2698

[9] Prasanna GE, Gheena S. A study of empathy across students from 4 health disciplines among 1st years and Final years [Internet]. Vol. 9, Research Journal of Pharmacy and Technology. 2016. p. 1472. Available from: http://dx.doi.org/10.5958/0974360x.2016.00286.9
[10] Gunasekaran G, Abilasha R. Tooth Sensitivity Among Residential University Students In Chennai [Internet]. Asian Journal of Pharmaceutical and Clinical Research. 2016. p. 63. Available from:

http://dx.doi.org/10.22159/ajpcr.201 6.v9s2.13228

[11] Abitha T, Santhanam A. Correlation between bizygomatic and maxillary central incisor width for gender identification [Internet]. Vol. 22, Brazilian Dental Science. 2019. p. 458-66. Available from: http://dx.doi.org/10.14295/bds.2019. v22i4.1775

[12] Uma PK, Ramani $P$, Sherlin $H$, Gheena S, Ramasubramanian A, Don KR, et al. Diet and exercise among students of a wellreputed dental college in Chennai: A questionnaire-based survey [Internet]. Vol. 2, International Journal of Orofacial Biology. 2018. p. 47. Available from: http://dx.doi.org/10.4103/ijofb.ijofb _- 19

[13] Krishnan RP, Ramani P, Sherlin HJ, Sukumaran G, Ramasubramanian A, Jayaraj G, et al. Surgical Specimen 
Handover from Operation Theater to

Laboratory: A Survey. Ann

Maxillofac Surg [Internet]. 2018 Jul;8(2):234-8. Available from: http://dx.doi.org/10.4103/ams.ams 51_18

[14] Ahmed MA, Jouhar R, Ahmed N, Adnan S, Aftab M, Zafar MS, et al. Fear and Practice Modifications among Dentists to Combat Novel Coronavirus Disease (COVID-19) Outbreak [Internet]. Vol. 17, International Journal of Environmental Research and Public Health. 2020. p. 2821 . http://dx.doi.org/10.3390/ijerph1708 2821

[15] Sarbeen JI, Insira Sarbeen J, Gheena S. Microbial variation in climatic change and its effect on human health [Internet]. Vol. 9, Research Journal of Pharmacy and Technology. 2016. p. 1777. Available from:

http://dx.doi.org/10.5958/0974360x.2016.00359.0

[16] Sansare K, Gupta A, Khanna V, Karjodkar F. Oral tuberculosis: unusual radiographic findings [Internet]. $\quad$ Vol. 40, Dentomaxillofacial Radiology.
2011. p. 251-6. Available from: http://dx.doi.org/10.1259/dmfr/7504 7143

[17] Palati S, Ramani P, Herald. J. Sherlin, Gheena S, Don KR, Jayaraj $\mathrm{G}$, et al. Age Estimation of an Individual Using Olze's Method in Indian Population-A CrossSectional Study [Internet]. Vol. 13, Indian Journal of Forensic Medicine \& Toxicology. 2019. p. 121. Available from: http://dx.doi.org/10.5958/09739130.2019 .00179 .8

[18] Ashraf M, Amin P, Mehr S. Impact of the coronavirus (COVID-19) outbreak on obstetric and gynaecological surgery - A letter to the editor on "Impact of the coronavirus (COVID-19) pandemic on surgical practice - Part 2 (surgical prioritisation)". Correspondence [Internet]. International Journal of Surgery. 2020. Available from: http://dx.doi.org/10.1016/j.ijsu.2020 .05 .077

[19] Manohar J, Abilasha R. A Study on the Knowledge of Causes and Prevalance of Pigmentation of Gingiva among Dental Students 
[Internet]. Vol. 10, Indian Journal of

Public Health Research \& Development. 2019. p. 95. Available from:

http://dx.doi.org/10.5958/0976-

5506.2019.01859.x

[20] Huang Z, Wang M, Qiu L, Wang N, Zhao Z, Rui J, et al. Seasonality of the transmissibility of hand, foot and mouth disease: a modelling study in Xiamen City, China. Epidemiol Infect [Internet]. 2019 Dec 30;147:e327. Available from: http://dx.doi.org/10.1017/S0950268819 002139

[21] Hannah R, Ramani P, Herald. J. Sherlin, Ranjith G, Ramasubramanian A, Jayaraj G, et al. Awareness about the use, Ethics and Scope of Dental Photography among Undergraduate Dental Students Dentist Behind the lens [Internet]. Vol. 11, Research Journal of Pharmacy and Technology. 2018. p. 1012. Available from: http://dx.doi.org/10.5958/0974360x.2018.00189.0

[22] Harrita S, Santhanam A. Determination of Physical Height Using Clinical Crown Height of Deciduous Teeth
[Internet]. Vol. 13, Indian Journal of Forensic Medicine \& Toxicology. 2019. p. 23. Available from: http://dx.doi.org/10.5958/0973-

9130.2019.00255.x

[23] Sheriff KAH, Ahmed Hilal Sheriff K, Santhanam A. Knowledge and Awareness towards Oral Biopsy among Students of Saveetha Dental College [Internet]. Vol. 11, Research Journal of Pharmacy and Technology. 2018. p. 543. Available from: http://dx.doi.org/10.5958/0974360x.2018.00101.4

[24] Sukumaran G, Padavala S. Molar incisor hypomineralization and its prevalence [Internet]. Vol. 9, Contemporary Clinical Dentistry. 2018. p. 246. Available from: http://dx.doi.org/10.4103/ccd.ccd_161_ 18

[25] Ahad M, Gheena S. Awareness, attitude and knowledge about evidence based dentistry among the dental practitioner in Chennai city [Internet]. Vol. 9, Research Journal of Pharmacy and Technology. 2016. p. 1863. Available from: http://dx.doi.org/10.5958/0974360x.2016.00380.2 